\title{
DEMOCRACIA, JUSTIÇA E ESTADO DE EXCEÇÃO: passado presente
}

\author{
Tásso Araújo Brito*
}

RESUMO: Violência contra parcelas da sociedade, descrença nas instituições democráticas e agentes do estado infligindo torturas contra aqueles que estão sob sua custodia, elementos que corroem o projeto democrático brasileiro. Entre o passado de ditadura militar-civil e nosso atual momento passamos a perceber como práticas tidas como exceção se transformaram em regras que afetam as vidas de muitos cidadãos brasileiros. O presente artigo investiga essas experiências políticas para questionar que democracia é essa em que vivemos.

PALAVRAS-CHAVE: Ditadura; Julgamento; Prisões; Torturas

\section{Democracy, justice and state of exception: past present}

\begin{abstract}
Violence against portions of society, disbelief in democratic institutions and agents of the state who inflict torture against those who are in their custody are elements that corrode the Brazilian democracy. Between the past of the military-civilian dictatorship and the current moment we realize how practices that have been considered exceptions have become rules that affect the life of many Brazilian citizens. The present paper investigates these political experiences to ask which democracy have we been living in.
\end{abstract}

KEYWORDS: Dictatorship; Prisons; Torture; Trial

\section{Democracia, justicia y estado de excepción: pasado presente}

RESUMEN: La violencia contra las partes de la sociedad, la incredulidad en las instituciones democráticas y los agentes del estado infligiendo torturas a los que están bajo su custodia, los elementos que corroen el proyecto democrático brasileño. Entre dictadura militar-civil pasado y nuestro presente llegamos a entender cómo las prácticas tomadas como una excepción convirtieron en normas que afectan a la vida de muchos ciudadanos brasileños. Este artículo investiga estas experiencias políticas a cuestionar que la democracia es aquella en la que vivimos.

PALABRAS CLAVE: Dictadura; El encarcelamiento; El juicio; La tortura

\footnotetext{
* Mestrado em História no Programa de Pós-graduação em História da Universidade Federal de Pernambuco. Atualmente professor substituto no Departamento de Educação da Universidade Federal Rural de Pernambuco. Contato: Universidade Federal Rural de Pernambuco, Departamento de Educação, Rua Dom Manuel de Medeiros, s/n, Dois Irmãos, 52171-900, Recife - PE, Brasil. tasso.brito@gmail.com.
} 


\title{
Parte I
}

Hoje, uma viatura policial segue com jovens negros presos, algemados e torcendo para chegarem vivos ao seu destino. No passado, um navio negreiro zarpou da costa da África com destino ao Brasil carregado de negros presos, grilhões e torcendo para chegarem vivos ao seu destino. Apesar de serem cenas imaginadas, as duas apresentam uma verossimilhança com o presente e passado de nosso país. A população negra brasileira não foi integrada ao projeto de cidadania democrática no Brasil.

Mulheres, que até o começo do século XX nem mesmo votavam, hoje são vítimas de violência e de uma gritante desvalorização trabalhista na forma salarial ${ }^{1}$. Povos indígenas, que tiveram suas terras invadidas ao longo de nossa história, hoje são mortos às centenas em conflitos por terra pelo Brasil. Ambos, também, não foram integrados ao projeto de cidadania democrática no Brasil.

Esta parcela da população é trazida a um ordenamento social através de seu processo de marginalização e exclusão social. São excluídos para que possam ser incluídos. A exclusão inclusiva é um conceito do filósofo italiano Giorgio Agamben $^{2}$, no qual aquele que é excluído de fato não é posto de fora da sociedade, mas sim incluído na sociedade através de sua exclusão. Ou seja, não existe exclusão, mas sim uma colocação da vida em um determinado lugar para atender os cálculos de poder.

Então, resta-se perguntar que democracia é esta que vivemos, na qual parcelas significativas de nossa sociedade são excluídas. Os mecanismos usados para tais exclusões são atos de exceção que convivem com as regras democráticas. É preciso, como escreveu Walter Benjamin, reelaborar outro conceito de história para entender tais relações. Na tese VIII de seu texto Sobre o conceito de História escreveu:

\begin{abstract}
A tradição dos oprimidos nos ensina que o "estado de exceção" em que vivemos é na verdade a regra geral. Precisamos construir um conceito de história que corresponda a essa verdade. Nesse momento, perceberemos que nossa tarefa é originar um verdadeiro estado de exceção; com isso, nossa posição ficará mais forte na luta contra o fascismo. Este se beneficia da circunstância de que seus adversários o enfrentam em nome do progresso, considerado como uma norma histórica. O assombro com o fato de que os episódios que vivemos no séculos XX "ainda" sejam possíveis, não é um assombro filosófico. Ele não gera nenhum conhecimento, a não ser o conhecimento de que a concepção de história da qual emana semelhante assombro é insustentável. (BENJAMIN, p.226, 1994)
\end{abstract}

Ao analisarmos a situação de negros, mulheres e indígenas é gritante como estes, de forma geral, não tem acesso igualitários aos mecanismos que constituem a democracia. Desta 
forma muitas vidas experimentam verdadeiros estados de exceção, transformando a democracia em uma prática incomum.

Vidas submetidas à exceção como regra assemelham-se a uma figura do direito romano, o homo sacer, que segundo Giorgio Agamben (2010) eram aqueles que não foram condenados a morte, mas seu assassinato não era considerado homicídio. Ou seja, sua vida não entrava na urbe, entendida como a cidade em sua dimensão política e jurídica, não apenas como espaço físico. Estavam submetidos a um estado de exceção permanente.

Jacques Rancière (2014), em $O$ ódio à democracia, defende que muitos são aqueles que temem uma grande crise da democracia que seria gerada pela própria atividade democrática. Ou seja, o exercício pleno daquilo que se entende por democracia, causaria o colapso da mesma, pois não existiria espaço de participação para todos. Desta forma, houve em vários momentos medidas para evitar esta crise. Incluindo-se várias formas de estados de exceção nas democracias. Essa descrença na democracia plena urdiu uma legalização do próprio estado de exceção, e em momentos de crises o estado de exceção aflora.

Em uma entrevista publicada no blog da editora Boitempo ${ }^{3}$, Giorgio Agamben foi perguntado sobre as crises econômicas e políticas dos países europeus. Ele respondeu:

A crise atual tornou-se um instrumento de dominação. Ela serve para legitimar decisões políticas e econômicas que de fato desapropriam cidadãos e os desproveem de qualquer possibilidade de decisão. Na Itália isso é muito claro. Aqui um governo foi formado em nome da crise e Berlusconi voltou ao poder apesar de basicamente contrariar a vontade do eleitorado. Esse governo é tão ilegítimo quanto a dita constituição europeia. Os cidadãos da Europa devem ter claro que esta crise interminável - assim como um estado de emergência - é incompatível com a democracia.

A crise justificou as ações do estado de exceção no seio de governos tidos como democráticos. E a crise prolongada que muitos estados ocidentais vem atravessando pavimenta um caminho para um estado de exceção permanente. Isto é um entrave à construção da democracia plena, na qual todos possam ter acesso aos bens históricos e socialmente produzidos.

No Brasil, a crise econômica e política ganhou contornos dramáticos através do processo de impedimento da presidenta Dilma Rousseff. Um ato de exceção que levou ao poder um governo pouco representativo da população brasileira, que propõem criticáveis reformas ao nosso sistema trabalhista, previdenciário, educacional e econômico. Mudanças pautadas no discurso da crise. Todo o processo do impedimento e do estabelecimento do novo governo aconteceu diante do olhar da Justiça que deu seu aval. 


\section{Parte II}

O estado de exceção, segundo Agamben (2004), se faz valer de sua força para uma constante criação das leis. Para este autor, o estado de exceção não é aquele que funciona sem ordenamento jurídico, mas é aquele que pode suspender o direito para preservar uma determinada ordem. Assim, a exceção convive com ordenamentos políticos e jurídicos dos mais diversos. Desta forma, o estado de exceção brasileiro se situa no lugar de indistinção entre a existência e a não existência de legalidade, é desta zona de indistinção que o estado cria as regras e, por não sair desta zona, é que podemos chamá-lo de estado de exceção. Como analisam Foucault (2003) e Agamben (2010), esta zona é ocupada através da força, tanto coercitiva quanto a força do convencimento.

Para Agamben, o estado de exceção está em contato com as formas de governar ao longo da história, para ele o fim da escravidão na América do Norte, a Revolução Francesa e o Nazismo foram momentos nos quais os governos se utilizaram dos estados de exceção. Ainda segundo o filosofo, recentemente a democracia dos Estados Unidos da América, sem instaurar uma ditadura ou qualquer outro regime não democrático, se valeu de atos exceção e/ou excepcionais para tomar medidas jurídicas que, nas palavras do filósofo, "não podem ser compreendidas no campo do direito.” (2004 p.14). Escreveu Giorgio Agamben:

\footnotetext{
A novidade da "ordem" do presidente Bush está em anular radicalmente o estatuto jurídico do individuo, produzindo, dessa forma, um ser juridicamente inominável e inclassificável. Os talibãs capturados no Afeganistão, além de não gozarem do estatuto POW (prisioneiro de guerra) de acordo da convenção de Genebra, tampouco gozam daquele de acusado segundo a lei norte-americana.(AGAMBEN, 2004 p.14)
}

Os atos de exceção não anulam a democracia americana, coexistem com ela. Ainda segundo Agamben (2004 p.15), o termo estado de exceção é estranho à tradição anglosaxônica do direito, assim como na italiana e francesa. Porém, estas tradições se referem a estes atos excepcionais como Lei Marcial e Poderes Emergenciais (anglo-saxão); Decretos de Urgência e Estado de Sítio, que pode ser político ou fictício (Itália e França). Estado de Exceção é comum a tradição alemã.

As terminologias italiana, francesa e anglo-saxônica, indicam a guerra (lei marcial e estado de sítio) como a situação de origem para se estabelecer os atos de exceção. Estendemse para o âmbito civil as esferas da autoridade militar em tempos de guerra, assemelhando às esferas bélicas as demais esferas do social. Por isso, em muitos países, como o Brasil, os 
presidentes são, também, a maior autoridade militar. Desta forma, lei marcial ou o estado de sítio são capazes de unificar os poderes executivo, legislativo e judiciário na figura de mando militar, que, como já dito, em muitos países é o chefe do executivo. Essa união, para Giorgio Agamben (2004 p.19), tem se tornado a tendência do paradigma governamental desde a Primeira Guerra Mundial.

Estas medidas excepcionais, segundo Agamben (2004 p.22), são a maneira que algumas tradições jurídicas ocidentais encontraram para regulamentar o estado de exceção. Assim, o estado de sítio ou lei marcial são formas que as tradições jurídicas criaram para dar caráter legal ao estado de exceção.

As medidas são muitas vezes previstas em constituições democráticas. No Brasil, apenas a constituição de $1937^{4}$ não faz menção à possibilidade de se decretar um estado de sítio. Desta maneira, exceções à democracia são previstas no Brasil desde a constituição de 1891 até a nossa atual, de 1988. As relações entre a democracia e o estado de exceção não são antagônicas.

A república brasileira mantém um diálogo jurídico com o estado de sítio. Os artigos das constituições brasileiras que versam sobre as medidas excepcionais são em geral parecidos. A constituição de 1891 prevê que é função do presidente:

Art 20. declarar em estado de sitio um ou mais pontos do territorio nacional na emergencia de aggressão por forças estrangeiras ou de commoção interna, e approvar ou suspender o sitio que houver sido declarado pelo Poder Executivo, ou seus agentes responsaveis, na ausencia do Congresso (BRASIL, 1891) (Sic)

Constituição de 1934:

Art 175 - O Poder Legislativo, na iminência de agressão estrangeira, ou na emergência de insurreição armada, poderá autorizar o Presidente da República a declarar em estado de sítio qualquer parte do território nacional (BRASIL, 1934)

Constituição de 1947:

Art 206 - O Congresso Nacional poderá decretar o estado de sítio nos casos:

I - de comoção intestina grave ou de fatos que evidenciem estar a mesma a irromper;

II - de guerra externa. (BRASIL, 1947)

Constituição de 1967:

Art 152 - O Presidente da República poderá decretar o estado de sitio nos casos de:

I - grave perturbação da ordem ou ameaça de sua irrupção;

II - guerra. (BRASIL, 1967)

Constituição de 1988: 
Art. 137. O Presidente da República pode, ouvidos o Conselho da República e o Conselho de Defesa Nacional, solicitar ao Congresso Nacional autorização para decretar o estado de sítio nos casos de:

I - comoção grave de repercussão nacional ou ocorrência de fatos que comprovem a ineficácia de medida tomada durante o estado de defesa;

II - declaração de estado de guerra ou resposta a agressão armada estrangeira.

Parágrafo único. O Presidente da República, ao solicitar autorização para decretar o estado de sítio ou sua prorrogação, relatará os motivos determinantes do pedido, devendo o Congresso Nacional decidir por maioria absoluta. (BRASIL, 1988)

As constituições de 1891, 1934, 1967 e 1988 apresentam a possibilidade de um estado de sítio diante de uma necessidade, seja a guerra contra um inimigo externo ou o confronto de uma desordem interna. O direito da necessidade, segundo o filósofo Giorgio Agamben (2004), é baseado na máxima latina necessitas legem non habet, que pode ser traduzida como a necessidade não tem lei. Desta forma as constituições brasileiras transformam o estado de exceção em estado de sítio, atribuindo uma pretensa regulação por lei sobre aquilo que não era normatizado. Elas enquadram na forma de lei aquilo que não é a lei, se aplicando naquilo que se exclui.

Outro aspecto importante sobre o direito da necessidade é que este se apresenta como uma decisão política. Decretar o estado de sítio é prerrogativa daqueles que estão instituídos no controle das instituições, no caso brasileiro o executivo e/ou legislativo. O que faz este mecanismo jurídico ter o objetivo político de preservar um determinado status quo, ou seja, decretar um estado de sítio pode ter usos contra poderes constituintes, contra o novo que se confronta com o estabelecido, contra alguma força nova que põe em cheque o modelo político vigente. Acreditamos que até o momento a democracia é a melhor forma de governo, porém, isso não implica dizer que no futuro não possa existir outra forma melhor. Por isso, é preocupante essa proteção jurídica e política da democracia. A democracia é protegida para que esta não tome outros rumos se não aqueles desejados pelo poder estabelecido.

Os Atos Institucionais (AI), criados pela ditadura Militar-Civil, foram mecanismos usados para exceção e regra se fundirem. O AI-1 em seu texto introdutório versou:

A revolução vitoriosa se investe no exercício do Poder Constituinte. Este se manifesta pela eleição popular ou pela revolução. Esta é a forma mais expressiva e mais radical do Poder Constituinte. Assim, a revolução vitoriosa, como Poder Constituinte, se legitima por si mesma. Ela destitui o governo anterior e tem a capacidade de constituir o novo governo. Nela se contém a força normativa, inerente ao Poder Constituinte. Ela edita normas jurídicas sem que nisto seja limitada pela normatividade anterior à sua vitória. Os Chefes da revolução vitoriosa, graças à ação das Forças Armadas e ao apoio inequívoco da Nação, representam o Povo e em seu nome exercem o Poder Constituinte, de que o Povo é o único titular. O Ato Institucional que é hoje editado pelos Comandantes-em-Chefe do Exército, da Marinha e da Aeronáutica, em nome da revolução que se tornou vitoriosa com o apoio da Nação na sua quase totalidade, se destina a assegurar ao novo governo a ser 
instituído, os meios indispensáveis à obra de reconstrução econômica, financeira, política e moral do Brasil, de maneira a poder enfrentar, de modo direto e imediato, os graves e urgentes problemas de que depende a restauração da ordem interna e do prestígio internacional da nossa Pátria. A revolução vitoriosa necessita de se institucionalizar e se apressa pela sua institucionalização a limitar os plenos poderes de que efetivamente dispõe. (BRASIL, 1964)

Mas, ao mesmo tempo em que o movimento golpista se declara poder constituinte, o primeiro artigo versava: “Art. $1^{\circ}$ - São mantidas a Constituição de 1946 e as Constituições estaduais e respectivas Emendas, com as modificações constantes deste Ato." (BRASIL, 1964). Desta forma, a exceção e a regra eram elementos que estavam juntos.

Os demais atos institucionais vão aproximar ainda mais o estado de direitos e o estado de exceção. Para o historiador Daniel Aarão Reis (2014 p.123), os Atos Institucionais são o cerne do estado de exceção na ditadura militar-civil. Para este historiador a revogação dos mecanismos, em 1979, pôs um fim a ditadura brasileira, porém assumindo a perspectiva teórica do Agamben, o estado de exceção não é o sinônimo de ditadura.

No Brasil, o regime ditatorial se valeu da força do estado de exceção para implementar suas políticas, principalmente aquelas criadas para reprimir os adversários políticos. Com uma política marcada fortemente pelo ideário da Doutrina da Segurança Nacional, os opositores do regime foram transformados em inimigos da nação através da Lei de Segurança Nacional (LSN), um dos mecanismos que criavam um estado de exceção no Brasil.

\section{Parte III}

Em 1935, foi criada a primeira Lei de Segurança Nacional. Isto permitiu que o governo de Getúlio Vargas transferisse certos atos considerados crimes para uma legislação especial. Com os acirramentos políticos, ela passou a ser usada contra indivíduos considerados inimigos daquele regime. Com o fim do Estado Novo a lei foi mantida até ser substituída por outra em $1953^{5}$.

A nova Lei de Segurança Nacional foi elaborada no mundo em Guerra Fria, fortemente marcada com as preocupações de preservar o sistema político-econômico brasileiro de ameaças externas. O historiador Eric Hobsbawm (2009) afirma que neste período, de forma geral, se acreditava que a instabilidade geopolítica entre o bloco capitalista e o comunista era tamanha que a humanidade estava à beira de uma terceira guerra mundial de proporções apocalípticas por conta do uso de armas nucleares e de destruição em massa. Segundo Raffaele Nocera (2012), o governo dos Estados Unidos da América conseguiu lograr êxito em manter muitos países latino-americanos no eixo capitalista. Conforme Marina 
Franco (2012), a definição principal de segurança continental era baseada na ameaça comunista.

Com essas preocupações, da ameaça comunista externa, uma nova Lei de Segurança Nacional, criada em 1953 (lei $n^{\circ} 1.802$ ), traz em seu texto:

Art. $1^{\circ}$ São crimes contra o Estado e a sua ordem política e social os definidos e punidos nos artigos desta lei, a saber:

Art. $2^{\circ}$ Tentar:

I - submeter o território da Nação, ou parte dêle, à soberania de Estado estrangeiro;

II - desmembrar, por meio de movimento armado ou tumultos planejados, o território nacional desde que para impedi-lo seja necessário proceder a operações de guerra;

III - mudar a ordem política ou social estabelecida na Constituição, mediante ajuda ou subsídio de Estado estrangeiro ou de organização estrangeira ou de caráter internacional;

IV - subverter, por meios violentos, a ordem política e social, com o fim de estabelecer ditadura de classe social, de grupo ou de indivíduo; (BRASIL, 1953).

A Lei de Segurança Nacional de 1953 adiciona a questão da ameaça estrangeira às preocupações de segurança governamental. A LSN de 1935 era uma lei de 52 artigos, onde nenhum deles é voltado para esta preocupação com ameaça estrangeira. Cada lei de segurança corresponde a preocupações do seu tempo, luta os embates do seu momento presente.

Mas, em comum as duas leis há o fato de que ambas em seus textos visam proteger o status quo vigente. São mecanismos que tornam, juridicamente, um determinado projeto político em um projeto de nação e aqueles contrários, a ele, transformam-se em inimigos.

Enquanto isso na década de 50, a preocupação militar gravitava em torno dos conceitos da Doutrina de Segurança Nacional, que, de acordo com João Roberto Martins Filho (2009), era fortemente baseada na produção intelectual e experiência francesa durante a rebelião argelina. Ainda segundo este cientista social, o conceito de guerre révolutionnaire era fulcral, pois é o que vai nortear as ações de repressão. Sobre esse novo conceito, João Roberto Martins Filho escreve:

A Guerra Revolucionária é diferente da guerra convencional porque coloca o recurso às armas no final e não no começo do conflito. Sua evolução pode ser explicada em cinco etapas. Na primeira etapa, os revolucionários agem sem declarar seus objetivos, preparando cautelosamente a população que se pretende conquistar. Na segunda, efetiva-se a construção de organizações subversivas e formam-se bases que subvertem a capacidade de ação governamental. É a fase das manifestações, tumultos e atos de sabotagem. A terceira etapa é a da formação de grupos armados, que iniciam ações de menor escala, destinadas a corroer os poderes constituídos. É a fase do terrorismo. A penúltima etapa é a do estabelecimento de zonas liberadas ou bases d'appui, onde o Exército regular não consegue mais entrar. (...) A quinta fase é a conquista do poder numa ofensiva final. (MARTINS FILHO, 2009 p.183-184) 
$\mathrm{Na}$ Escola Superior de Guerra, a guerra revolucionaria passou por mudanças, entre suas variações se estabeleceu o conceito de inimigo interno (MARTINS FILHO, 2009). Para combater esta ameaça a segurança nacional era preciso estabelecer uma guerra total contra os mesmos. Segundo o cientista social, Nilson Borges, a guerra total implica que:

Toda a política nacional, portanto, é reorientada em função da segurança, sendo que as esferas militar e política são indissoluvelmente ligadas, de maneira que a política deixa de ser uma arte civil para se transformar em arte militar. A guerra interna ou a eliminação do inimigo interno passa a ser uma estratégia imposta pelos imperativos da segurança nacional (BORGES, 2012 p. 28).

Depois do golpe de 1964, a Lei de Segurança Nacional vai ser usada como um dos principais mecanismos jurídicos para reprimir aqueles que eram considerados inimigos do Estado. A lei de 1953 vai ser a base de acusação daqueles que foram nomeados de subversivos e ou comunistas.

A Lei de Segurança Nacional faz parte de uma maquinaria que possibilitou a repressão aos adversários do regime. Mas, ela já era usada antes de 1964. Em 1956, o Partido Comunista em Pernambuco teve algumas de suas lideranças presas. Dentre esses membros do partido comunista podemos citar: Ivo Valença, Aristides Ferreira Alves, Hugo Ferreira e Antônio Ferreira da Silva. Formando o processo judicial $n^{\circ} 1546^{6}$. Todos eles foram acusados na Lei de Segurança Nacional, em seu nono artigo que é:

Art. $9^{\circ}$ Reorganizar ou tentar reorganizar, de fato ou de direito, pondo logo em funcionamento efetivo, ainda que sob falso nome ou forma simulada, partido político ou associação dissolvidos por fôrça de disposição legal ou fazê-lo funcionar nas mesmas condições quando legalmente suspenso. (BRASIL, 1953)

O Partido Comunista estava na ilegalidade desde 1947. A prisão das lideranças comunistas é baseada nesta transgressão. O relatório policial, peça informativa do processo jurídico, aponta também para outra direção:

Orgulhamo-nos de haver prestado, embora modestamente, um serviço de real importância ao nosso querido Estado e ao nosso amado Brasil. Desarticulando o "Comité Regional de Pernambuco", do Partido Comunista do Brasil, embargamos os passos daqueles que, obedientes ás palavras de ordem oriundas de Moscou, tentavam articular movimentos que, certamente, visavam operações de maior vulto no tocante á subversão da ordem. (Sic)

A ideia de um inimigo externo estava presente, pois um dos perigos que representava o Partido Comunista era de ser recebedor do discurso oriundo de Moscou. Com a ditadura instaurada em 1964, tal categoria, a do inimigo externo, ganhou mais destaque.

A força política que aplicava a lei mudou e isto também mudou sua aplicabilidade. A força é o que garante a lei. Como ressalta o filósofo Jacques Derrida: 
Existem, certamente, leis não aplicadas, mas não há lei sem aplicabilidade, e não há aplicabilidade ou "enforceability" da lei sem força, quer seja direta ou não, física ou simbólica, exterior ou interior, brutal ou sutilmente discursiva - ou hermenêutica - , coercitiva ou reguladora etc. (DERRIDA, 2010 p.8-9)

O governo ditatorial articulou outras formas de aplicar as leis já vigentes. Uma das grandes mudanças para a Lei de Segurança Nacional foi realizada por modificação na constituição, via AI-2, que em seu oitavo artigo:

Art. $8^{\circ}-\mathrm{O} \S 1^{\circ}$ do art. 108 da Constituição passa a vigorar com a seguinte redação: $\S 1^{\circ}$ - Esse foro especial poderá estender-se aos civis, nos casos expressos em lei para repressão de crimes contra a segurança nacional ou as instituições militares.

$\S 2^{\circ}$ - Competem à Justiça Militar, na forma da legislação processual, o processo e julgamento dos crimes previstos na Lei $n^{\circ} 1.802$, de 5 de janeiro de 1953.

$\S 3^{\circ}$ - A competência da Justiça Militar nos crimes referidos no parágrafo anterior com as penas aos mesmos atribuídas, prevalecerá sobre qualquer outra estabelecida em leis ordinárias, ainda que tais crimes tenham igual definição nestas leis. (BRASIL, 1965)

Civis foram levados aos tribunais da justiça militar. O que antes era julgado na esfera comum, passou a ter um foro diferenciado. Muitos advogados encaravam a justiça militar como um lugar de menor possibilidade de absolvição de seus clientes. O historiador Antônio Torres Montenegro (2011), ao contar a história de um grupo de trabalhadores rurais envolvidos em disputas trabalhistas em tempos de ditadura Militar-Civil, afirma que era constante o esforço dos advogados para que a questão de seus clientes não fosse considerada subversão da ordem e, portanto, não fosse levado à justiça militar.

Em 1967, junto à nova constituição emergiu uma nova Lei de Segurança Nacional (lei $\mathrm{n}^{\circ}$ 314). Segundo a jurista Kathia Martin-Chenut (2009), essa nova lei tornava os cidadãos responsáveis pela segurança do país e o novo texto previa tipos penais amplos e vagos.

Com a decretação do AI-5 foi vetado a possibilidade de impetrar habeas corpus para os crimes relativos à Lei de Segurança Nacional. Fato este que tornava a defesa nos tribunais militares ainda mais difícil.

Cada vez mais ia se tornando complexo o sistema judicial da ditadura. Segundo Kathia Martin-Chenut (2009): "Essa complexidade não traduz necessariamente incapacidade ou incompetência jurídica, pelo contrário, ela representa uma estratégia que torna difícil o exercício de direitos pelos cidadãos e entrave ao controle internacional. (2009, p.239)".

A existência de uma legalidade foi uma das estratégias de legitimação do governo ditatorial. E segundo o historiador Anthony Pereira (2010), a presença desta preocupação com a justiça no Brasil é uma das principais diferenças entre as ditaduras no cone sul em meados do século XX. 
Foi no uso da lei que o estado ditatorial brasileiro conseguiu pôr em prática muitas de suas políticas. A ditadura e a constituição dialogaram, o estado se valeu da força da lei para fazer o regime funcionar.

\title{
Parte IV
}

Uma parcela dos advogados de presos políticos e seus cliente usaram da visibilidade dos julgamentos para expor as praticas ilegais que muitos agentes do estado brasileiro praticavam contra aqueles que eram considerados inimigos do regime ditatorial. Segundo Wilma Antunes Maciel (2006) 25\% dos processos que formam o arquivo Brasil Nunca Mais $^{7}$ relatam a tortura dos réus e de testemunhas. Esta autora ao escrever sobre a defesa de presos políticos relata algumas práticas dos advogados. Entre a atuação de alguns defensores, ela destacou:

Já o advogado Francisco Antonio de Moraes da Cunha, na defesa de Antonio Roberto Espinosa e Dilma Rousseff, atuou como um verdadeiro tribuno em uma longa arguição, contestando as irregularidades processuais. Reiterou as denúncias de Espinosa de que prestaram depoimentos sob terríveis torturas (MACIEL 2006 p.180)

Gregório Bezerra foi um dos principais líderes do Partido Comunista (PC) daquele momento. Ele foi preso nos primeiros dias do golpe de $1964^{8}$ e relatou à auditoria militar sua tortura, e o escrivão assim registrou:

\begin{abstract}
por ocasião de sua prisão foi mandado recolher ao forte das Cinco Pontas, sendo transferido imediatamente para o Parque de Motomecanização sob o comando do Ten. Cel. VILLOCH, onde foi o interrogado recebido a cano de ferro e com a cabeça rachada e todo ensanguentado, começaram os espancamentos bárbaros pelo próprio Cel. VILLOCH e um grupo de sargentos comandados pelo mesmo, dizendo que os sargentos não tivesse pena do interrogado; que com os pés em carne viva foi o interrogado arrastado pelas, digo, amarado pelo pescoço pelas ruas do bairro de Casa Forte, inclusive na frente do CPOR, onde Cel. VILLOCH, fez um comício concitando oficiais e alunos a linchar o interrogado, isto além das palavras de baixo calão usadas pelo referido Ten. Cel VILLOCH, inclusive ferindo a dignidade de sua família, dizendo o Tem. Cel. "EU SOU IBADEANO"; que também foi levado até a frente à residência do referido Ten. Cel. VILLOCH e foi além da residência do Ten. Cel. Villoch voltando novamente defronte à residência do referido Ten. Cel. (Sic)
\end{abstract}

O escrivão, que relata o testemunho do réu Gregório Bezerra, o faz acentuando a tortura sofrida pelo líder comunista através de adjetivação. Ao nomear de "bárbara", a tortura sofrida, assim como o termo "arrastado pelo pescoço", ele torna pejorativa à prática de tortura.

A Ditadura Militar-Civíl não admitia a existência de torturas e mortes realizadas por agentes do estado a serviço do regime. O governo de Castelo Branco realizou investigações 
em vários estados para apurar as acusações de tortura. O general Ernesto Geisel, então, chefe da casa civil, foi encarregado de proceder à operação. Ele chegou à conclusão que não existia tortura no Brasil ou no máximo admitia a existência de alguns excessos (MONTENEGRO, 2012).

Gregório Bezerra, em sua autobiografia, relembra que na prisão foi visitado pelos generais Ernesto Geisel e Olimpo Mourão Filho, no Forte das Cinco Pontas, após sua seção de tortura (BEZERRA, 2011 p.539). Manuel Messias ${ }^{9}$, preso político arrolado no mesmo processo que Gregório Bezerra, em entrevista ao projeto Marcas da Memória- História oral da anistia no Brasil $^{10}$, recordou-se de ter sido entrevistado por um militar a mando do marechal Estevão Taurino de Rezende. Segundo Antônio Montenegro (2011), este marechal foi presidente da Comissão Geral de Investigação.

Como analisa a cientista social Maria José Rezende (2001), a ditadura tal qual outras formas de governo, buscava legitimação. Empreendeu as mais variadas ações para isso. Ernesto Geisel ao negar a tortura no Brasil contribui para as estratégias de legitimidade do governo ditatorial.

O Cel. Hélio Ibiapina, responsável pelo Inquérito Policial Militar (IPM), em que se baseia o processo 88/64, no qual Gregório Bezerra, Manuel Messias e mais 38 cidadãos brasileiros eram réus; alega que havia uma grande estratégia de difamação contra aqueles que tomaram o poder em 1964. Escreveu ele na página 8 deste IPM:

Foram presos e os dias se passaram sem que houvesse chegado a este encarregado de IPM qualquer sorte de reclamação até que, jornalistas a soldo de potencias estrangeiras, protegidos por uma imprensa frustrada que não informa, deforma, numa irresponsabilidade ilimitada, dentro de exato esquema de rearticulação comuno-inconformados, formando a frente única dos atingidos pela afirmação da autoridade, pela volta à legalidade, pela esperança de trabalho, progresso e ordem e sobretudo pela moralidade administrativa, iniciam uma campanha de desmoralização de pessoas e de medidas do governo. (sic)

O coronel Ibiapina, no IPM, negou as acusações que denunciavam as práticas de torturas nos tribunais. Militares e civis que deram o golpe de 1964 não reconheciam a existência de tais práticas. Antônio Bandeira, então coronel do Exército, relata sua memória ao livro de entrevistas Vencedores e vencidos o movimento de 1964 em Pernambuco (2004), sobre a crítica às torturas realizadas pelos golpistas:

Em toda revolução essas ações mesquinhas, mais exaltadas, fogem a ação da chefia. Intenção não houve, em absoluto; ao contrário. A intenção era de respeito. Tanto é que, quando houve a necessidade de deposição do governado, mandamos um oficial superior conduzi-lo até o quartel do 14 RI. O prefeito Pelópidas Silveira também foi conduzido ao quartel do $7^{\circ} \mathrm{RO}$. E assim a maioria. Porém houve alguns excessos, infelizmente incontroláveis, frutos mais de um estado emocional exacerbado. 
Tivemos conhecimento, posteriormente, de alguns excessos como aqueles praticados no ex-sargento Gregório (BANDEIRA, 2004 p.28)

Os golpistas não reconheciam a tortura enquanto prática governamental, quando no máximo era fruto de ações individuais. Nos tribunais, muitos advogados usaram das denuncias de tortura para tentar desqualificar as provas contra seus clientes. Mércia Albuquerque, advogada de Gregório Bezerra e Manuel Messias, nas alegações finais, escreveu:

Sob todos os aspectos, esse processo é uma monstruosidade jurídica, Há, nele, graves nulidades, tanto de forma, como de conteúdo. Sua peça informativa - o inquérito policial-militar - tem manchas de sangue. Do sangue de espancamentos de réus e de testemunhas. Muitos dos denunciados sofreram os piores suplícios - que a Nação conheceu, em detalhes. Gregório quase foi morto ${ }^{11}$.

Mércia Albuquerque aponta as torturas contra os réus como algo que invalidava o processo em sua peça informativa, o IPM. Um dos direitos básicos do réu é não produzir provas contra ele mesmo. O estado de exceção suspendeu tal direito. Assim, é nesta suspensão que a lei se aplica em um estado de exceção.

$\mathrm{Na}$ violação dos direitos individuais dos réus, o estado de exceção brasileiro aplicou a lei. Desta forma, a justiça conviveu com práticas de torturas e os juízes, concordando ou não com elas, tinham de realizar os julgamentos com este elemento.

Nem sempre, em tribunais militares, tais denúncias aconteceram da mesma maneira como as feitas por Gregório Bezerra e Mércia Albuquerque. Wilma Antunes Maciel (2006), ao analisar nove processos em que membros da Vanguarda Popular Revolucionaria (VPR) são réus, relata que em dois processos distintos sobre o mesmo réu, houve variação. Em um era relatado a sua tortura e em outro não.

A tortura de Gregório Bezerra aconteceu em uma praça pública, sendo na época amplamente noticiada, por isso negá-la não foi uma estratégia empregada pelos golpistas. $\mathrm{O}$ relato do coronel Bandeira aponta para isso. Na mesma entrevista já citada, ele admite que em alguns casos houve torturas e cita Gregório Bezerra como exemplo. Por isso, neste caso, torna-se muito difícil negar a tortura.

Hoje, as torturas ainda são um instrumento de investigação usado ilegalmente pela polícia. Acionado contra pobres, principalmente jovens negros, em conflito com a lei, por vezes ganhando os noticiários, ou por vezes ficando no cotidiano das localidades menos favorecidas de nossas cidades. Pratica recorrente, mas noticiada e tida como exceção. 
Até sob a tutela do estado a tortura é uma pratica comum, admitida no relatório final $^{12}$ da Comissão Parlamentar de Inquérito (CPI) da violência contra a juventude, de relatoria do senador Linderbergh Farias, que assim registrou:

A tortura, aliás, merece um capítulo à parte no relato do dia a dia de meninos e meninas sob custódia do Estado brasileiro. A prática de tortura, segundo apurou a Renade, ocorre em todos os estados do Brasil e de maneira relativamente frequente, não apenas de maneira punitiva, mas como instrumento cotidiano utilizado para fomentar medo entre os adolescentes e até como simples instrumento de sadismo. O uso de medicamentos psiquiátricos dentro das unidades socioeducativas, muitas vezes com o propósito declarado de ser um meio de adormecer adolescentes, chamou a atenção dos técnicos que fizeram as visitas. (RELÁTORIO CPI DA VIOLÊNCIA CONTRA A JUVENTUDE, 2016, p 78)

Assim, a justiça continua a conviver com essa prática, que marca a ferro quente nossa história. Transforma em regra aquilo que é tido como exceção. Assola o cotidiano das localidades mais empobrecidas. Faz da democracia um sonho distante.

Enquanto grandes empresários e políticos tem a delação premiada que diminui suas penas em grandes escândalos financeiros e políticos. Como canta Mc Carol, em sua música intitulada Delação Premiada:

Três dias de tortura Numa sala cheia de rato É assim que eles tratam o bandido, favelado

Bandido rico e poderoso

Tem sela separada Tratamento vip e delação premiada

Assim, podemos perceber que o projeto de cidadania democrática tem cor e status social. A democracia e estado de exceção convivem, quer seja nas práticas legais, quer seja nas ilegais. Uma marca de nossa história.

\section{Notas}

\footnotetext{
${ }^{1}$ Para mais dados sobre a violência contra mulheres: WAISELFISZ, Julio Jacobo. Mapa da violência 2015 homicídios de mulheres no Brasil. In: http://www.mapadaviolencia.org.br/pdf2015/MapaViolencia_2015_mulheres.pdf

2 AGAMBEN, Giorgio. Homo Sacer: O poder soberano e a vida nua. Belo Horizonte: Editora UFMG, 2010.

3 https://blogdaboitempo.com.br/2013/07/17/a-crise-infindavel-como-instrumento-de-poder-uma-conversa-comgiorgio-agamben/

A

constituição

encontra-se

disponível

em:

http://www.planalto.gov.br/ccivil_03/constituicao/constituicao37.htm, acesso em 20 de março de 2015.
} 


\footnotetext{
${ }^{5}$ Ver mais informações no site da Fundação Getúlio Vargas, disponível, acesso em 05-04- 15: https://cpdoc.fgv.br/producao/dossies/AEraVargas1/anos3037/RadicalizacaoPolitica/LeiSegurancaNacional

${ }^{6}$ Processo de $\mathrm{n}^{\mathrm{o}}$ 1546, Memorial da Justiça de Pernambuco, na caixa de processos históricos.

${ }^{7} \mathrm{O}$ arquivo do Brasil Nunca Mais foi desenvolvido pelo Conselho Mundial de Igrejas e pela Arquidiocese de São Paulo nos anos oitenta, sob a coordenação do Rev. Jaime Wright e de Dom Paulo Evaristo Arns. A iniciativa teve três principais objetivos: evitar que os processos judiciais por crimes políticos fossem destruídos com o fim da ditadura militar, tal como ocorreu ao final do Estado Novo, obter informações sobre torturas praticadas pela repressão política e que sua divulgação cumprisse um papel educativo junto à sociedade brasileira. Para mais informações ver http://bnmdigital.mpf.mp.br/pt-br/

${ }^{8}$ Todas as informações foram retiradas da autobiografia de Gregório Bezerra intitulada Memórias (2011) e de seu prontuário do DOPS, $\mathrm{n}^{\circ}$ 5774, fundo SSP: 12185, arquivo público Estadual de Pernambuco João Emerenciano

${ }^{9}$ Manuel Messias era secretário do Partido Comunista em Pernambuco no momento do golpe. Entrevistado em Olinda-PE, em 28 de Abril de 2011.

${ }^{10}$ Projeto financiado pela Comissão de Anistia do Ministério da Justiça e realizado por três universidades UFPE, UFRJ e UFRGS. Formando um acervo de entrevistas com homens e mulheres que tiveram suas vidas de alguma forma atingidas pela ditadura militar-civil vigente no Brasil entre 1964 a 1985. As entrevistas realizadas pela equipe da UFPE estão acessíveis em: https://www.youtube.com/channel/UCc_o5ZHJRo3GDtpUqCvvXg

11 Arquivo Pessoal Mércia Albuquerque, caixa Gregório Bezerra, no acervo da ONG DHNET na cidade de Natal- RN

12 Disponível em http://www12.senado.leg.br/noticias/arquivos/2016/06/08/veja-a-integra-do-relatorio-da-cpido-assassinato-de-jovens
}

\section{Referências Bibliográficas}

AGAMBEN, Giorgio. Homo Sacer: O poder soberano e a vida nua. Belo Horizonte: Editora UFMG, 2010.

Estado de Exceção. São Paulo: Boitempo, 2004

BENJAMIN, Walter. Obras escolhidas volume 1: Magia e técnica, arte e política. São Paulo: Ed. Brasiliense, 1994.

Documentos de cultura, documentos de barbárie: escritos escolhidos.

São Paulo: Cultrix Editora. São Paulo: Editora da Universidade de São Paulo, 1986.

BEZERRA, Gregório. Memórias. São Paulo, SP: Editora Boitempo, 2011.

BORGES, Nilson. A Doutrina de Segurança Nacional e os Governos Militares. In: FERREIRA, Jorge; DELGADO. Lucilia de Almeida Neves. Brasil Republicano V.4: $O$ Tempo de Ditadura: Regime Militar e Movimentos Sociais em Fins do Século XX. Rio de Janeiro: Civilização Brasileira, 2012.

BRASIL. Ato Institucional I. Acesso em 27- 07-14: http://www.planalto.gov.br/ccivil_03/AIT/ait-01-64.htm

$$
\text { Lei de Segurança Nacional, 1953. Acesso em 27- 07-14: }
$$
http://www.planalto.gov.br/ccivil_03/leis/1950-1969/L1802.htm

Lei de Segurança Nacional, 1967. Acesso em 28 - 07 -14: http://www2.camara.leg.br/legin/fed/declei/1960-1969/decreto-lei-314-13-marco-1967366980-publicacaooriginal-1-pe.html

BRAYNER, Flávio Henrique Albert. Partido comunista em Pernambuco: mudança e conservação na atividade do partido comunista brasileiro em Pernambuco 1956 -1964. Recife: FUNDAJ/Editora Massangana, 1989. 
CANEIRO, Ana; CIOCCARI, Marta. Retrato da Repressão no Campo - Brasil 1962-1985 Camponeses torturados, mortos e desaparecidos. Brasília: MDA, 2010.

FOUCAULT, Michel. A verdade e as formas jurídicas, Rio de Janeiro: NAU, 2003.

FRANCO, Marina. Anticomunismo, subversíon y patria: Construcciones culturales $e$ ideológica em la Argentina de lós 70. In CALLANDRA, Bernadetta. FRANCO, Marina. La guerra fria cultural en América latina. Buenos Aires: Biblos, 2012.

HOBSBAWN, Eric J. Era dos extremos: o breve século xx (1914-1991). São Paulo: Companhia das Letras, 1995.

MACIEL, Wilma Antunes. O Capitão Lamarca e a VPR Repressão Judicial no Brasil. São Paulo, Sp: Alameda, 2006.

MARTIN-CHENUT, Kathia. O sistema penal de exceção em face do direito internacional dos direitos humanos. In SANTOS, C.M. et all. Desarquivando a ditadura: Memória e justiça no Brasil. São Paulo: Editora Hucitec, 2009.

MARTINS FILHO, João Roberto. Tortura e ideologia: os militares brasileiros e a doutrina da guerre révolutionnaire (1959-1974). In SANTOS, C.M. et all. Desarquivando a ditadura: Memória e justiça no Brasil. São Paulo: Editora Hucitec, 2009.

MONTENEGRO, Antônio Torres. História e Memória de lutas políticas. In. Marcas da Memória: história oral da anistia no Brasil. Recife: Editora da UFPE, 2012.

Ação trabalhista, repressão policial e assassinato em tempos de regime militar. In Topoi, v. 12, n. 22, jan.-jun. 2011 p. 228-249. Acesso em 30 de janeiro de 2015: http://www.revistatopoi.org/numero_atual/topoi22/topoi\%2022\%20\%20artigo\%2013.pdf

NOCERA, Raffaele. La guerra fria en América Latina reflexiones acerca da la dimensíon político-institucional. CALLANDRA, Bernadetta. FRANCO, Marina. La guerra fria cultural en América latina. Buenos Aires: Biblos, 2012.

PEREIRA, Anthony W. Ditadura e Repressão: O Autoritarismo e o Estado de Direito no Brasil, no Chile e na Argentina. São Paulo, SP: Paz e Terra, 2010.

PORFÍRIO, Pablo. Medo, comunismo e revolução Pernambuco (1959-1964). Recife: Ed. Universitária UFPE, 2009.

RANCIÈRE, Jacques. O ódio à democracia. São Paulo: Boitempo, 2014.

REIS FILHO, Daniel Aarão. Ditadura e Democracia no Brasil. Rio de Janeiro: Ed. Zahar, 2014.

REZENDE, Maria José. A ditadura militar no Brasil: repressão e pretensão de legitimidade (1964-1984). Londrina: Ed. Uel, 2001.

WAISELFISZ, Julio Jacobo. Mapa da violência 2015 homicídios de mulheres no Brasil. In: http://www.mapadaviolencia.org.br/pdf2015/MapaViolencia_2015_mulheres.pdf 